\title{
Real-World Pattern of Treatment and Clinical Outcomes of EGFR-Mutant Non-Small Cell Lung Cancer in a Single Academic Centre in Quebec
}

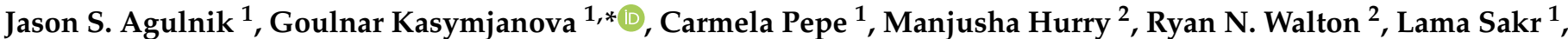 \\ Victor Cohen ${ }^{1}$ and David Small ${ }^{1}$ \\ 1 Peter Brojde Lung Cancer Centre, Jewish General Hospital, McGill University, \\ Montreal, QC H3T 1E2, Canada; jagulnik@jgh.mcgill.ca (J.S.A.); cpepe@jgh.mcgill.ca (C.P.); \\ lsakr@jgh.mcgill.ca (L.S.); vcohen@jgh.mcgill.ca (V.C.); dsmall@jgh.mcgill.ca (D.S.) \\ 2 AstraZeneca Canada, Mississauga, ON L4Y 1M4, Canada; manjusha.hurry@astrazeneca.com (M.H.); \\ ryan.walton@astrazeneca.com (R.N.W.) \\ * Correspondence: gkasymja@jgh.mcgill.ca
}

Citation: Agulnik, J.S.; Kasymjanova, G.; Pepe, C.; Hurry, M.; Walton, R.N.; Sakr, L.; Cohen, V.; Small, D.

Real-World Pattern of Treatment and Clinical Outcomes of EGFR-Mutant Non-Small Cell Lung Cancer in a Single Academic Centre in Quebec. Curr. Oncol. 2021, 28, 5179-5191. https://doi.org/10.3390/ curroncol28060434

Received: 2 November 2021 Accepted: 3 December 2021 Published: 7 December 2021

Publisher's Note: MDPI stays neutral with regard to jurisdictional claims in published maps and institutional affiliations.

Copyright: (c) 2021 by the authors Licensee MDPI, Basel, Switzerland. This article is an open access article distributed under the terms and conditions of the Creative Commons Attribution (CC BY) license (https:// creativecommons.org/licenses/by/ $4.0 /)$.

\begin{abstract}
The discovery of EGFR tyrosine kinase inhibitors (TKI) for the treatment of EGFR mutant (EGFRm) metastatic NSCLC is regarded as a landmark in lung cancer. EGFR-TKIs have now become a standard first-line treatment for EGFRm NSCLC. The aim of this retrospective cohort study is to describe real-world patterns of treatment and treatment outcomes in patients with EGFRm metastatic NSCLC who received EGFR-TKI therapy outside of clinical trials. One hundred and seventy EGFRm metastatic NSCLC patients were diagnosed and initiated on first-line TKI therapy between 2004 and 2018 at the Peter Brojde Lung Cancer Centre in Montreal. Following progression of the disease, $137(80 \%)$ patients discontinued first-line treatment. Moreover, 80/137 (58\%) patients received second-line treatment, which included: EGFR-TKIs, platinum-based, or single-agent chemotherapy. At the time of progression on first-line treatment, 73 patients were tested for the T790M mutation. Moreover, 30/73 (41\%) patients were found to be positive for the T790M mutation; 62/80 patients progressed to second-line treatment and 20/62 were started on third-line treatment. The median duration of treatment was 11.5 (95\% CI; 9.62-13.44) months for first-line treatment, and 4.4 (95\% CI: 1.47-7.39) months for second-line treatment. Median OS from the time of diagnosis of metastatic disease was 23.5 months (95\% CI: 16.9-30.1) and median OS from the initiation of EGFR-TKI was 20.6 months (95\% CI: 13.5-27.6). We identified that ECOG PS $\leq 2$, presence of exon 19 deletion mutation, and absence of brain metastases were associated with better OS. A significant OS benefit was observed in patients treated with osimertinib in second-line treatment compared to those who never received osimertinib. Overall, our retrospective observational study suggests that treatment outcomes in EGFRm NSCLC in real-world practice, such as OS and PFS, reflect the result of RCTs. However, given the few observational studies on real-world treatment patterns of EGFR-mutant NSCLC, this study is important for understanding the potential impact of EGFR-TKIs on survival outside of clinical trials. Further real-world studies are needed to characterize patient outcomes for emerging therapies, including first-line osimertinib use and combination of osimertinib with chemotherapy and potential future combination of osimertinib and novel anticancer drug, outside of a clinical trial setting.
\end{abstract}

Keywords: NSCLC; EGFR; TKI treatment; real-world treatment pattern

\section{Introduction}

Lung cancer is the most common cancer worldwide, accounting for 2.1 million new cases and 1.8 million deaths in 2018 [1]. In Canada, in 2020, an estimated 21,200 people died from lung cancer. This represents $25 \%$ of all cancer deaths [2]. The treatment of lung cancer is the fastest developing area and the guidelines are continuously evolving, 
compared to other cancers [3]. A major advancement in the treatment of non-small cell lung cancer (NSCLC) has been the discovery of genomic abnormalities (or oncogenic drivers) that drive the development of certain types of lung cancer [4-6]. To date, several driver mutations have been identified with the most common being GTPase (guanosine triphosphate) KRAS (Kirsten rat sarcoma viral oncogene homolog), epidermal growth factor receptor (EGFR), anaplastic lymphoma kinase (ALK), and human epidermal growth factor 2 (HER2) mutations [7]. In Western countries, EGFR mutations are present in 10-35\% of NSCLC cases, but the prevalence of these mutations is not uniform among populations; it tends to be more prevalent in females, non-smokers, and patients with bronchioloalveolar features in tumor specimens [8-10].

The discovery of EGFR tyrosine kinase inhibitors (TKI) for the treatment of EGFRm metastatic NSCLC was regarded as a landmark in lung cancer. The economic model, where a new intervention is compared to the current standard of treatment, is primarily based on randomized clinical trials (RCT). RCT evidence leads to regulatory approval and incorporation of novel treatments into practice. It is well known from RCTs that first and second-generation EGFR-TKI therapies are superior to chemotherapy in EGFR-mutant (EGFRm) metastatic lung cancer patients [8,11-17]. As a result, EGFR-TKIs have now become a standard first-line treatment for EGFRm NSCLC [18,19]. Recently, osimertinib, a third-generation EGFR-TKI has been approved in multiple countries, including Canada, for the treatment of patients with locally advanced or metastatic EGFRm NSCLC in the first setting based on the superiority of osimertinib compared to first-generation EGFR-TKI [20].

However, there is little published observational data on the survival of EGFRm NSCLC patients treated with EGFR-TKI outside of RCTs [21-23]. In particular, some of the realworld data that has yet to be published includes population characteristics at diagnosis of EGFRm NSCLC, treatment types, and associated survival outcomes.

The aim of this retrospective cohort study is to describe real-world patterns of treatment and treatment outcomes in patients with EGFRm metastatic NSCLC who received EGFR-TKI therapy outside of clinical trials. To our knowledge, this is the first study reporting the trajectory of treatment and outcomes of EGFRm NSCLC patients in the province of Quebec. Although the results of this analysis will never replace RCTs, they do offer complementary information for physicians, patients, and policymakers.

\section{Materials and Methods}

\subsection{Objectives}

This is a retrospective observational cohort study of an EGFRm metastatic NSCLC patient population which aims to assess real-world clinical treatment patterns, and treatment outcomes.

Primary objective:

- To describe the treatment patterns and outcomes including real-world progression-free survival (rwPFS), response rate (RR) and overall survival (OS) for EGFRm NSCLC patients treated at an academic centre in Montreal, Canada

Secondary objective:

- To describe demographic and clinical characteristics at diagnosis of EGFRm NSCLC patients and their prognostic value

\subsection{Study Design}

This is an observational retrospective cohort study of patients diagnosed with metastatic EGFRm NSCLC at the Peter Brojde Lung Cancer Centre in Montreal, Quebec. Data were extracted from the lung cancer registry. The cancer registry contains data on all lung cancer cases treated at our center since 2001. As a routine practice, every patient diagnosed with lung cancer is entered into the registry in real time. The information is updated as treatment changes. The study was approved by the Jewish General Hospital Research Ethics Committee (Protocol: JGH-07-025). 


\subsection{Patients Selection Criteria}

For purpose of this study, all the cases treated between 2004 and 2018 were screened for inclusion: eligible patients had to be initiated on first-line EGFR-TKI treatment for metastatic EGFRm NSCLC.

We extracted the following information:

a. Patient characteristics including date of metastatic NSCLC diagnosis, stage at the time of initial diagnosis, sex, age at the time of diagnosis, ethnicity, Eastern Cooperative Oncology Group performance status (ECOG PS), smoking history.

b. Tumor characteristics include the stage of the disease, presence or absence of brain metastases, and type of EGFR mutations.

c. Type of molecular tests: the evolution of the EGFR test for our center is recorded as: Denaturing high-pressure liquid chromatography (DHPLC) from 2004 to 2007; single gene sequencing from 2008 to 2010; real-time polymerase chain reaction (PCR) from 2011 to 2014 and next-generation sequencing (NGS) from 2014 to current.

d. Real-world treatment patterns identified in our clinical practice include comprehensive treatment history from diagnosis to current treatment, treatment duration, and modality sequencing (targeted therapy, chemotherapy, radiotherapy, and best supportive care).

Patients who were initiated with systemic chemotherapy prior to EGFR results and subsequently switched to EGFR-TKI prior to disease progression were also included in the analysis. To ensure the sufficient maturity of survival data and the homogeneity of treatment, only patients diagnosed with metastatic NSCLC from September 2004 to December 2018 were used for the study. The database was locked for analysis on 31 May 2019. Patients referred to our center for a second opinion were excluded due to a lack of follow-up information.

\subsection{Outcome Measures and Definitions}

The index date was set to date of diagnosis of metastatic NSCLC.

a. Treatment patterns are described by line of treatment. For the purpose of this study, first-line therapy was defined as EGFR-TKI treatment commencing after the index date.

b. Duration of EGFR-TKI treatment was calculated as the time (in months) elapsed between the start and end dates of the treatment.

c. Response to treatment was defined by the treating physician as per RECIST criteria and was based on radiographic imaging (CT/PET) and categorized for analysis purposes as an objective response (complete response (CR) + partial response (PR), stable disease (SD) and progressive disease (PD).

d. rwPFS was defined as the time between initiation of EGFR-TKI and clinician-defined progression based on RECIST [24]. In patients who were initiated with chemotherapy, but subsequently were tested positive for EGFR mutation, disease progression was calculated from the start of EGFR-TKI treatment to the date of progression on this treatment.

e. $\quad$ OS is defined as the time from index date to the date of death or last follow-up. Patients were censored if they were lost to follow-up or the event (death) did not occur within the study duration.

\subsection{Statistical Analysis}

Demographics, clinical characteristics, and treatment patterns are described using frequencies and proportions for categorical data and using means with standard deviation or medians with the associated $95 \%$ confidence interval (CI) for numeric data. Time variables (OS, rwPFS) are reported as medians with 95\% CI using Kaplan-Meier statistics. 
To avoid immortal time bias, the landmark survival method was used for osimertinib survival analysis. Landmark time was set as a start date of second-line therapy. Only events that occurred during that period were counted for this analysis.

Cox regression analysis was performed to identify prognostic factors for survival. The following factors were included in the model: sex, race, smoking, ECOG PS, type of EGFR mutation, type of EGFR-TKI testing.

Statistical analyses were conducted using IBM SPSS statistics 20 software for Windows.

\section{Results}

\subsection{Patients}

Between September 2004 and Dec 2018, 1229 patients were diagnosed with metastatic NSCLC patients. Of those $170(12 \%)$ patients were EGFRm and started on first-line EGFRTKI treatment.

Table 1 summarizes the characteristics of the study cohort. The majority of patients were female (71\%), Caucasian (69\%) and life-long non-smokers (62\%); the mean (SD) age was 65 (12) years. Forty-two patients (25\%) were initially diagnosed with early/locally advanced EGFRm NSCLC and later progressed to the metastatic stage: 31 of them had surgery and 11 received curative-intent radiation. The most common molecular alterations were exon 19 deletion (58\%) and exon 21 (L858R) (37\%) mutations. Fifty-one patients presented with brain metastasis at the time of diagnosis and received brain radiation (WBRT or SRS).

Table 1. Baseline demographic and clinical characteristics of patients.

\begin{tabular}{|c|c|}
\hline Characteristics & $N=170 N(\%)$ \\
\hline Age at diagnosis (y), interquartile range (IQR) & 65 (IQR: 18.25) \\
\hline \multicolumn{2}{|l|}{ Sex } \\
\hline Female & $121(71)$ \\
\hline Male & $49(29)$ \\
\hline \multicolumn{2}{|l|}{ Race } \\
\hline Caucasian & $117(69)$ \\
\hline Asian & $45(27)$ \\
\hline Black & $8(4)$ \\
\hline \multicolumn{2}{|l|}{ Smoking } \\
\hline Never-smoker & $106(62)$ \\
\hline Ever-smoker & $64(38)$ \\
\hline \multicolumn{2}{|l|}{ ECOG PS } \\
\hline $0-1$ & $151(89)$ \\
\hline 2 & $19(11)$ \\
\hline$>2$ & 0 \\
\hline \multicolumn{2}{|l|}{ Stage at Diagnosis } \\
\hline Early stage & $23(14)$ \\
\hline Locally advanced & $19(11)$ \\
\hline Metastatic & $128(75)$ \\
\hline \multicolumn{2}{|l|}{ EGFR mutation } \\
\hline Exon 19 (E19 del) & $98(58)$ \\
\hline Exon 21 (L858R) & $64(37)$ \\
\hline Exon $18(E 181)^{1}$ & $7(4)$ \\
\hline Exon 20 insertion (E20) & $1(1)$ \\
\hline \multicolumn{2}{|l|}{ Type of molecular test: } \\
\hline DhPLC (2004-2007) & $32(19)$ \\
\hline Single gene sequencing (2008-2010) & $17(10)$ \\
\hline Real-time PCR (2011-2014) & $48(28)$ \\
\hline NGS (2015-current) & $73(43)$ \\
\hline
\end{tabular}


Table 1. Cont.

\begin{tabular}{cc}
\hline Characteristics & $N=\mathbf{1 7 0 ~ N ~ ( \% )}$ \\
\hline Brain metastases at diagnosis & \\
Present & $51(30)$ \\
Not present & $119(70)$ \\
\hline Prior therapies for advanced/metastatic NSCLC before & \\
TKI & $26(15)$ \\
Yes & $144(85)$ \\
No &
\end{tabular}

\subsection{First Line EGFR-TKI Treatment at the Time of Diagnosis of Advanced Disease}

All 170 patients received EGFR-TKI treatment for metastatic EGFRm NSCLC (Figure 1). Twenty-six patients (15\%) diagnosed between 2004 and 2009 initially received a median of three cycles of systemic therapy prior to EGFR-TKI due to a delay in EGFR testing results. The EGFR-TKI treatment was initiated before the disease progression, and they were included in the analysis.

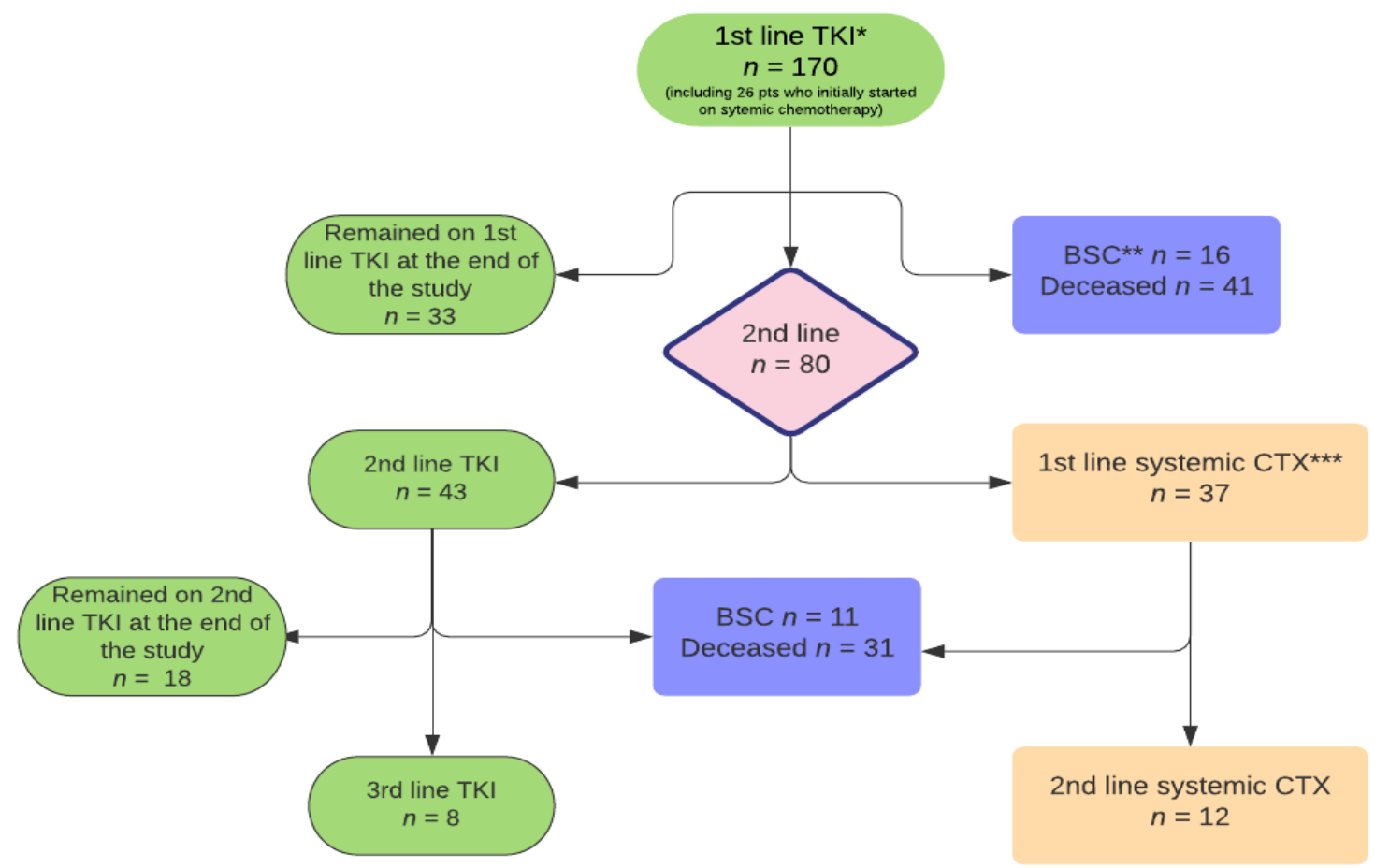

Figure 1. Flow chart of treatment. ${ }^{*}$ TKI—tyrosine kinase inhibitors; ${ }^{* *}$ BSC — best supportive care; ${ }^{* *}$ CTX — chemotherapy.

Of the 170 patients, $110(65 \%)$ patients received gefitinib, 56 (33\%) received erlotinib and $4(2 \%)$ received afatinib (Table 2). The median duration of first-line EGFR-TKIs treatment was 11.5 (95\% CI; 9.62-13.44) months; the range was 0.5 to 98 months. There was no significant difference in treatment duration among the types of EGFR-TKI used.

Table 3 summarizes the first-line treatment outcomes. Following progression of the disease, $137 / 170(81 \%)$ patients discontinued the first-line TKI treatment and 33/170 (19\%) patients were still on the first-line TKI at the end of the study (30 May 2019). Out of 137 patients who discontinued first-line TKI treatment, 57 (42\%) patients did not receive any further treatment: 41 patients died, and 16 patients received best supportive care. Eighty (58\%) patients received second-line treatment. 
Table 2. Lines EGFR-TKI treatment.

\begin{tabular}{|c|c|c|c|}
\hline EGFR-TKI & $\begin{array}{l}\text { Frequency } \\
\quad N(\%)\end{array}$ & $\begin{array}{l}\text { Duration of Treatment } \\
\text { Median (95\% CI) in Mo }\end{array}$ & $p$-Value \\
\hline \multicolumn{4}{|c|}{ First Line } \\
\hline Gefitinib & $110(64.7)$ & $11.7(8.03-15.36)$ & \multirow{3}{*}{0.535} \\
\hline Erlotinib & $56(32.9)$ & $11.4(7.4-15.29)$ & \\
\hline Afatinib & $4(2.4)$ & not reached & \\
\hline Total & $170(100)$ & $11.5(9.62-13.44)$ & \\
\hline \multicolumn{4}{|c|}{ Second Line } \\
\hline Osimertinib & $30(37.5)$ & $14.8(2.05-27.47)$ & \multirow{4}{*}{0.001} \\
\hline Erlotinib/Gefitinib & $5(6.3)$ & $2.1(0.45-3.89)$ & \\
\hline Afatinib & $8(10.0)$ & $1.9(036-3.64$ & \\
\hline Systemic chemo & $37(46.2)$ & $2.5(1.83-3.24)$ & \\
\hline Total & $80(100)$ & $4.4(1.47-7.39)$ & \\
\hline \multicolumn{4}{|c|}{ Third Line } \\
\hline Osimertinib & $2(10.0)$ & All censored & \multirow{4}{*}{$\mathrm{n} / \mathrm{a}$} \\
\hline Gefitinib/Erlotinib & $4(20.0)$ & All censored & \\
\hline Afatinib & $2(10.0)$ & All censored & \\
\hline Systemic chemo & $12(60.0)$ & $2.8(1.29-5.91)$ & \\
\hline Total & $20(100)$ & $3.9(0.74-6.46)$ & \\
\hline
\end{tabular}

Table 3. Outcomes of first-line treatment.

\begin{tabular}{|c|c|c|c|}
\hline First-Line Outcomes & $n(\%)$ & \multicolumn{2}{|c|}{$\begin{array}{l}\text { Reason for Discontinuation } \\
\qquad n(\%)\end{array}$} \\
\hline & & & \\
\hline \multirow{3}{*}{ Discontinued } & \multirow{3}{*}{$137(81)$} & Started second line & $80(58)$ \\
\hline & & $\mathrm{BSC}^{*}$ & $16(12)$ \\
\hline & & Died & $41(30)$ \\
\hline Total $n(\%)$ & $170(100)$ & & $137(100)$ \\
\hline
\end{tabular}

* BSC-best supportive care.

\subsection{Second Line Treatment for Advanced Disease}

The second-line treatment included: EGFR-TKIs, platinum-based chemotherapy or single-agent chemotherapy (Figure 1 and Table 2). Out of 80 patients who progressed and received second-line treatment, $43(54 \%)$ patients received next-generation EGFR-TKIs and $37(46 \%)$ were treated with systemic chemotherapy (Table 2). Among patients treated with systemic chemotherapy, 16/37 (43\%) received platinum-based regimens and 21/37 (57\%) received single-agent chemotherapy (Table 2). At the end of the study, 18 patients remained on second-line TKI. Of those, 15 were on osimertinib, 2 on afatinib and 1 on gefitinib.

T790M resistance mutation testing became available in 2015 and the presence of T790M resistance mutation was required for osimertinib treatment until January 2018. At the time of progression on first-line treatment, 73 patients were tested for the T790M mutation; $30 / 73(41 \%)$ patients were found to be positive for T790M. In 12/30 (40\%) of these cases, the T790M mutation was found on the circulating tumor DNA (ctDNA) test which became available in our center in 2017. The remaining $18(60.0 \%)$ patients were found to be T790M positive on tissue biopsy samples. All 30 T790M patients were treated with osimertinib as their second-line treatment. 
The median duration of second-line therapy was 4.4 (95\% CI: $1.47-7.39)$ months. The duration of osimertinib treatment was 14.8 (95\% CI: 2.05-27.47) months which was significantly longer compared to other TKI regimens (Table 2).

\subsection{Third Line Treatment for Advanced Disease}

Of the 80 patients who started second-line therapy, $62(78 \%)$ progressed. Of those, $20(32 \%)$ received a third-line therapy (Table 2$), 31(50 \%)$ died and $11(18 \%)$ received BSC. Among treated patients, the majority (12/20) received systemic chemotherapy and $8 / 20$ received other TKI therapies.

\section{5. rwPFS and OS Analysis}

The median follow-up was 37 months (range 5-122); 127 death events were observed. Median OS from the time of diagnosis of metastatic disease was 23.5 months (95\% CI: 16.9-30.1) and median OS from the initiation of EGFR-TKI was 20.6 months (95\% CI: 13.5-27.6). In patients without brain metastases, the OS was significantly better compared to those with brain metastases: 29.5 (95\% CI: 21.0-39.7) vs. 20.9 (95\% CI; 12.9-28.9) months respectively, $p=0.05$ (Figure $2 \mathrm{a}$ ). There was no difference in OS ( $p=0.60$ ) in comparing 26 patients who were switched to the EGFR-TKI before disease progression to 144 patients initiated on EGFR-TKI, 23.5 months (95\% CI: 16.9-30.1) and 25.1 months (95\% CI: 10.1-40.10), respectively.
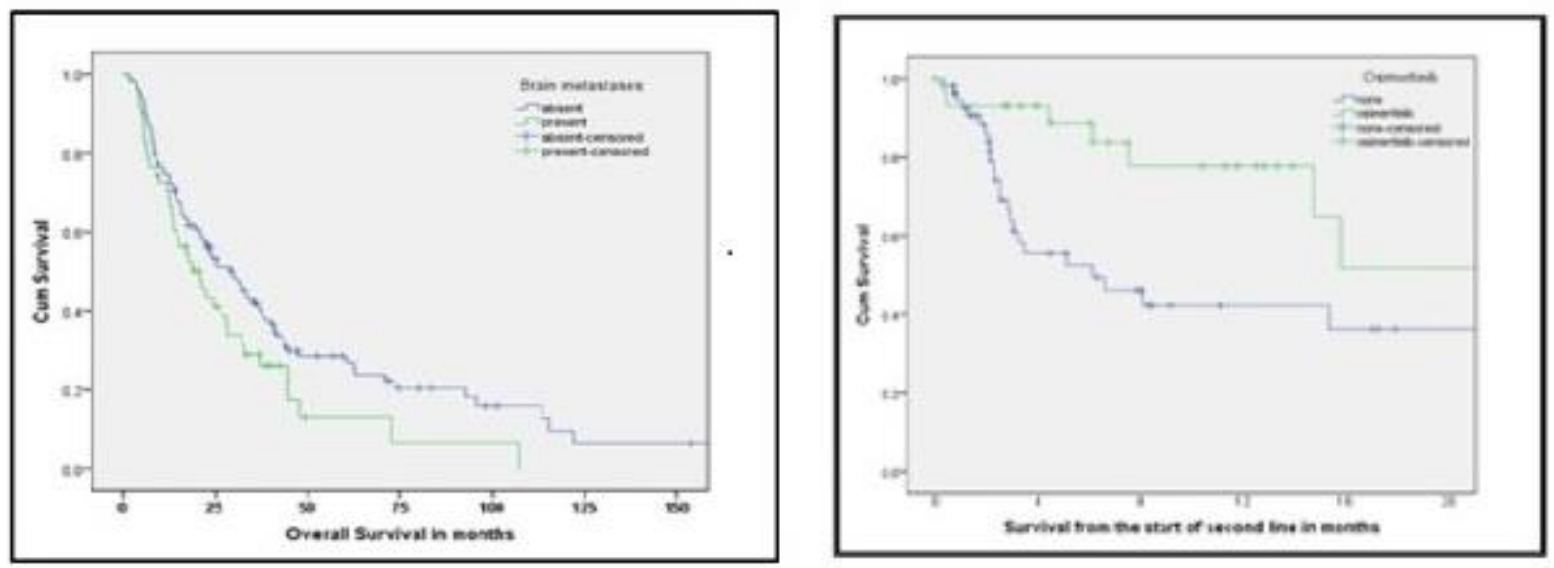

\begin{tabular}{|l|l|l|l|}
\hline Brain metastasis & Median & $95 \% \mathrm{Cl}$ \\
\hline Absent $n=119$ & 29.17 & 21.49 & 36.83 \\
\hline Present $n=51$ & 20.97 & 12.97 & 28.96 \\
\hline Overall & 24.00 & 17.95 & 30.05 \\
\hline Log Rank $p=0.05$ \\
\hline
\end{tabular}

(a)

\begin{tabular}{|l|l|l|l|}
\hline Osimertinib & Median & \multicolumn{2}{|l|}{$95 \% \mathrm{Cl}$} \\
\hline Yes $n=30$ & not & & \\
\hline No $n=50$ & 6.13 & 0.66 & 11.6 \\
\hline Overall & 15.37 & 6.14 & 24.6 \\
\hline \multicolumn{4}{|l}{ Log Rank $p=0.014$} \\
\hline
\end{tabular}

(b)

Figure 2. (a) OS in EGFRm patients with and without brain metastasis; (b) OS in EGFRm patients with and without osimertinib.

A significant survival benefit was observed in patients treated with osimertinib in second-line treatment compared to those who did not receive osimertinib when landmark survival analysis was used (Figure $2 \mathrm{~b}$ ). The starting point of second-line therapy was designated as a landmark time for survival. Median survival for patients on osimertinib was not reached at 24.8 months.

There were 170 patients available for analysis of the best response to treatment. The objective response rate of first-line EGFR-TKI therapy was 74.7\%: 83/170 (49\%) had CR/PR, $44 / 170(26 \%)$ had SD. The progression rate was $25.3 \%$ (43/170 patients). When compared to 
type of TKI used in the first-line setting, gefitinib provided a significantly higher response rate $(55 \%)$ and lower progression rate $(19.0 \%) p=0.005$ compared to erlotinib (Table 4).

Table 4. Response rate to first-line EGFR-TKI.

\begin{tabular}{ccccc}
\hline Response Rate (RR) & Afatinib & Gefitinib & Erlotinib & Total \\
\hline CR + PR $n(\%)$ & $4(100 \%)$ & $61(55.4 \%)$ & $18(32.1 \%)$ & $83(48.8 \%)$ \\
\hline $\operatorname{SD} n(\%)$ & 0 & $28(25.4 \%)$ & $16(28.6 \%)$ & $44(25.8 \%)$ \\
\hline $\operatorname{PD} n(\%)$ & 0 & $21(19.0 \%)$ & $22(39.3 \%)$ & $43(25.4 \%)$ \\
\hline Total $n(\%)$ & $4(100 \%)$ & $110(100 \%)$ & $56(100 \%)$ & $170(100 \%)$ \\
\hline
\end{tabular}

$\mathrm{CR}$-complete response; $\mathrm{PR}$ - partial response; SD—stable disease; PD—progressive disease. $p=0.005$.

rwPFS in first-line EGFR TKI therapy was 11.2 (95\% CI: 10.1-15.3) months. No difference in rwPFS among different EGFR-TKIs was observed. In the second-line treatment, PFS was $3.1(1.8-5.9)$ months with significantly $(p<0.001)$ prolonged PFS in patients treated with osimertinib 14.7 (95\% CI: 9.51-20.1) compared to other EGFR-TKIs 2.5 (1.88-3.18).

Several patient/tumor characteristics identified at the time of diagnosis of metastatic EGFRm NSCLC were considered to be potential prognostic factors for survival in univariate analysis: ECOG PS at index date ( $\leq 2$ vs. $>2$ ), presence of brain metastases (yes vs. no), and EGFR mutation (exon 19 (E19del) vs. exon 21 (L858R). Patients with exon 19 deletion had a significantly better OS (29.1months, 95\% CI: 22.9-35.3) when compared to exon 21 (16.03 months, 95\% CI: 11.2-20-8).

Multivariate Cox proportional hazards regression revealed that exon 19 (E19del) mutant patients experienced a lower risk of death (HR: 1.27; 95\% CI: 1.1-2.4) compared to other mutations, with adjustment for potential confounding variables (Table 5). Several other variables were associated with increased risk of death: ECOG PS > 2 (HR: $0.45 ; 95 \%$ CI: 0.3-0.8) and presence of brain metastases (HR: 0.65; 95\% CI: 0.4-0.9).

Table 5. Cox regression analysis for OS from the time of initiation of EGFR-TKI.

\begin{tabular}{|c|c|c|c|c|c|c|c|}
\hline \multirow{3}{*}{ Variable } & \multirow{3}{*}{ Comparator } & \multicolumn{6}{|c|}{ Cox Regression Analysis } \\
\hline & & \multicolumn{2}{|c|}{$\begin{array}{l}\text { Univariate } \\
\text { Analysis }\end{array}$} & \multirow{2}{*}{$p$-Value } & \multicolumn{2}{|c|}{$\begin{array}{c}\text { Multivariate } \\
\text { Analysis }\end{array}$} & \multirow{2}{*}{$p$-Value } \\
\hline & & HR & $95 \% \mathrm{CI}$ & & HR & $95 \% \mathrm{CI}$ & \\
\hline Female & Male & 0.91 & $0.62-1.3$ & 0.65 & 0.91 & $0.6-1.4$ & 0.66 \\
\hline Never-smoker & Ever-smoker & 0.83 & $0.58-1.2$ & 0.33 & 1.29 & $0.8-1.9$ & 0.21 \\
\hline ECOG PS > 2 & $\leq 2$ & 0.44 & $0.3-0.8$ & 0.005 & 0.45 & $0.3-0.8$ & 0.004 \\
\hline Exon $21 / 20 / 18$ & Exon $19 *$ & 1.39 & $1.0-1.9$ & 0.03 & 1.27 & $1.1-2.4$ & 0.05 \\
\hline Gefitinib ** & Erlotinib & 0.83 & $0.5-1.2$ & 0.31 & 1.10 & $0.7-1.7$ & 0.67 \\
\hline $\begin{array}{c}\text { Brain } \\
\text { metastasis } \\
\text { present }\end{array}$ & Absent & 1.50 & $1.0-2.2$ & 0.05 & 1.50 & $1.1-2.3$ & 0.04 \\
\hline Non-Asian & Asian & 1.26 & $0.8-1.9$ & 0.28 & 1.21 & $0.8-1.9$ & 0.43 \\
\hline NGS & $\begin{array}{c}\text { Alternate test } \\
\text { type }\end{array}$ & 2.07 & $1.4-3.0$ & $<0.001$ & 2.25 & $1.4-3.5$ & $<0.001$ \\
\hline
\end{tabular}

${ }^{*}$ For the purpose of this analysis, Exon 19 mutation compared to all the other. ${ }^{* *}$ Four patients treated with Afatinib excluded from these analyses. ${ }^{* *}$ NGS compared to combined previous testing technic.

\section{Discussion}

This review was performed to determine whether-in patients with EGFRm metastatic NSCLC - real-world outcomes achieved with TKI therapy are comparable to RCT outcomes reported in RCTs. Current Canadian guidelines recommend first-line EGFR-TKI monotherapy for EGFRm metastatic NSCLC patients, based on the results of superior OS, PFS and RR of first-line TKI compared to chemotherapy [18,25]. In 2018, osimertinib was approved for first-line treatment of EGFRm NSCLC and has become the new standard 
of care for these patients $[20,26]$. Osimertinib was not available for first-line treatment in our retrospective study. Despite the high efficacy of EGFR TKIs observed in metastatic EGFRm NSCLC, resistance emerges in most patients. The most common mechanism of resistance to first- and second-generation EGFR TKIs arises from the development of a secondary mutation in exon 20 (T790M) $[27,28]$. Our patients acquired a resistance to firstand second-generation TKIs after approximately 12 months of treatment in the first-line setting. At the time of progression, most patients were tested for the T790M resistance mutation. Forty-one percent were found to be positive and received osimertinib. The rate of the acquired T790M mutation resistance in our study was slightly lower than the 51-68\% reported by Oxnard et al. [29]. The second-line treatment patterns we identified are similar to those recommended in the guidelines [18,19]: 54\% of these patients were started on another TKI and 34\% started on systemic chemotherapy.

Some studies reported that osimertinib as second- or third-line TKI treatment outperforms systemic chemotherapy and first/second-generation TKIs [30-32]. The duration of second- or third-line treatment with osimertinib was in concordance with the AURA extension trial as well as the ASTRIS trial [30,33]. An RCT of second-line therapy with osimertinib, or cisplatin and pemetrexed, in NSCLC patients with T790M mutation, demonstrated superior efficacy for second-line osimertinib [31].

Real-world data reported from other Canadian provincial institutions demonstrated similar outcomes in terms of OS and PFS. However, the proportion of patients receiving second- or third-line treatment varied between institutions depending on local clinical practice [22,34].

Survival of 20.6 months from the time of TKI initiation in our study was comparable to 19-27 months from RCT results [32,35,36] as well as to 17.6-25 months from other realworld settings $[23,34,37,38]$. In our cohort, the OS in patients with brain metastasis was 21 months, which was similar to 22 months reported by Fujita et al. [39].

The response rate and PFS in the first-line TKI (gefitinib) were in concordance with the LUX Lung-7 trial [40]. Although it was reported by Ezeife et al. that afatinib use in pretreated patients prolongs survival by 5 months, it was not routinely used in our practice [41]. The significant prognostic factors for survival in our cohort were not different from those reported from the majority of the randomized controlled phase III trials [11,36,42] and in real-world studies [12,22,43]. Patients with good performance status, exon 19 deletion mutation and without brain metastases were found to have prolonged survival in our study. In addition, the method used for EGFR testing has also been found to be a prognostic factor. This could be explained by advances in technology of the testing methods.

This is a retrospective single-center study. While the registry provided accurate information on demographic characteristics, treatment patterns and survival data, as with all retrospective studies, there may be unmeasured confounding factors or unidentified sources of bias. Moreover, the number of patients treated with afatinib is relatively small, as only four patients received this treatment. In addition, the data were collected prior to the approval of osimertinib for first-line treatment and before the widespread use of immunotherapy treatments for metastatic NSCLC treatment.

\section{Conclusions}

Overall, our retrospective observational study suggests that treatment outcomes in EGFRm NSCLC in real-world practice, such as OS and PFS, reflect the result of RCTs. However, given the few observational studies on real-world treatment patterns of EGFRmutant NSCLC, this study is important for understanding the potential impact of EGFRTKIs on survival outside of clinical trials. We identified that ECOG PS $\leq 2$, presence of Exon 19 deletion mutation, and absence of brain metastases were associated with better OS. Further real-world studies are needed to characterize patient outcomes for emerging therapies, including first-line osimertinib use and combination of osimertinib with chemotherapy and potential future combination of osimertinib and novel anticancer drugs, outside of the clinical trial setting. 
Author Contributions: Conceptualization, J.S.A. and G.K.; methodology, J.S.A. and G.K.; software, G.K.; validation, J.S.A., G.K., M.H. and R.N.W.; formal analysis, G.K.; investigation, J.S.A., G.K., C.P., L.S., V.C. and D.S.; resources, J.S.A.; data curation, G.K.; writing-original draft preparation, G.K.; writing-review and editing, J.S.A., G.K., C.P., L.S., V.C., M.H., R.N.W. and D.S.; visualization, J.S.A.; supervision, J.S.A.; project administration, G.K.; funding acquisition, R.N.W. All authors have read and agreed to the published version of the manuscript.

Funding: This research was funded by AstraZeneca Canada, restricted grant.

Institutional Review Board Statement: This study was performed in line with the principles of the Declaration of Helsinki. Approval was granted by the Research Ethics Committee of Jewish General Hospital and authorized by Health Authorities. Approval Code: JGH-2007-35, 07-025. Approval Date: 12 February 2007.

Informed Consent Statement: The informed consent was waived by Research Ethic Committee as the study involves the collection of existing data which was entered in anonymous manner such that subjects cannot be identified directly or through identifiers linked to the subject.

Data Availability Statement: The data presented in this study are available on request from the corresponding author.

Conflicts of Interest: Agulnik S.J.-Astra Zeneca Advisory Board consultant. Kasymjanova G.—no conflict of interest. Pepe C.- - no conflict of interest. Hurry M.-Astra Zeneca employee. Walton R.N.-Astra Zeneca employee. Sakr L.-no conflict of interest. Cohen V.- no conflict of interest. Small D.- no conflict of interest.

\section{References}

1. World Health Organization. Cancer. Newsroom 2021. Available online: https://www.who.int/news-room/fact-sheets/detail/ cancer (accessed on 10 September 2021).

2. Canadian Cancer Statistics Advisory Committee. Canadian Cancer Statistics 2019. 2019. Available online: https://cancer.ca/en/ cancer-information/cancer-types/lung/statistics (accessed on 10 September 2019).

3. Shepherd, F.A. Targeted Therapy: The New Frontier. 2019. Available online: https://meetinglibrary.asco.org/record/168046 / slide (accessed on 10 September 2019).

4. Kris, M.G.; Johnson, B.E.; Berry, L.D.; Kwiatkowski, D.J.; Iafrate, A.J.; Wistuba, I.I.; Varella-Garcia, M.; Franklin, W.A.; Aronson, S.L.; Su, P.-F.; et al. Using Multiplexed Assays of Oncogenic Drivers in Lung Cancers to Select Targeted Drugs. J. Am. Med. Assoc. 2014, 311, 1998-2006. Available online: https://www.ncbi.nlm.nih.gov/pubmed/24846037 (accessed on 15 August 2020). [CrossRef]

5. Rosell, R.; Moran, T.; Queralt, C.; Porta, R.; Cardenal, F.; Camps, C.; Majem, M.; Lopez-Vivanco, G.; Isla, D.; Provencio, M.; et al. Screening for Epidermal Growth Factor Receptor Mutations in Lung Cancer. N. Engl. J. Med. 2009, 361, 958-967. Available online: https:/ / www.ncbi.nlm.nih.gov/pubmed/19692684 (accessed on 15 August 2020). [CrossRef] [PubMed]

6. Lim, C.; Tsao, M.; Le, L.W.; Shepherd, F.A.; Feld, R.; Burkes, R.L.; Liu, G.; Kamel-Reid, S.; Hwang, D.; Tanguay, J.; et al. Biomarker testing and time to treatment decision in patients with advanced nonsmall-cell lung cancer. Ann. Oncol. 2015, 26, 1415-1421. Available online: https://www.ncbi.nlm.nih.gov/pubmed/25922063 (accessed on 16 June 2020). [CrossRef] [PubMed]

7. Savas, P.; Hughes, B.; Solomon, B. Targeted therapy in lung cancer: IPASS and beyond, keeping abreast of the explosion of targeted therapies for lung cancer. J. Thorac. Dis. 2013, 5 (Suppl. 5), S579-S592. Available online: https://www.ncbi.nlm.nih.gov/ pubmed/24163750 (accessed on 15 September 2020). [PubMed]

8. Mok, T.S.; Wu, Y.-L.; Thongprasert, S.; Yang, C.-H.; Chu, D.-T.; Saijo, N.; Sunpaweravong, P.; Han, B.; Margono, B.; Ichinose, Y.; et al. Gefitinib or Carboplatin-Paclitaxel in Pulmonary Adenocarcinoma. N. Engl. J. Med. 2009, 361, 947-957. Available online: https:/ / www.ncbi.nlm.nih.gov/pubmed/19692680 (accessed on 10 September 2021). [CrossRef] [PubMed]

9. Jänne, P.A.; Wang, X.; Socinski, M.A.; Crawford, J.; Stinchcombe, T.E.; Gu, L.; Capelletti, M.; Edelman, M.; Villalona-Calero, M.A.; Kratzke, R.; et al. Randomized Phase II Trial of Erlotinib Alone or With Carboplatin and Paclitaxel in Patients Who Were Never or Light Former Smokers With Advanced Lung Adenocarcinoma: CALGB 30406 Trial. J. Clin. Oncol. 2012, 30, 2063-2069. Available online: https:/ / www.ncbi.nlm.nih.gov/pubmed/22547605 (accessed on 10 September 2021). [CrossRef] [PubMed]

10. Riely, G.J.; Pao, W.; Pham, D.; Li, A.R.; Rizvi, N.; Venkatraman, E.S.; Zakowski, M.F.; Kris, M.G.; Ladanyi, M.; Miller, V.A. Clinical Course of Patients with Non-Small Cell Lung Cancer and Epidermal Growth Factor Receptor Exon 19 and Exon 21 Mutations Treated with Gefitinib or Erlotinib. Clin. Cancer Res. 2006, 12, 839-844. Available online: https://www.ncbi.nlm.nih. gov/pubmed/16467097 (accessed on 10 September 2021). [CrossRef] [PubMed] 
11. Fukuoka, M.; Wu, Y.-L.; Thongprasert, S.; Sunpaweravong, P.; Leong, S.-S.; Sriuranpong, V.; Chao, T.-Y.; Nakagawa, K.; Chu, D.-T.; Saijo, N.; et al. Biomarker Analyses and Final Overall Survival Results from a Phase III, Randomized, Open-Label, First-Line Study of Gefitinib Versus Carboplatin/Paclitaxel in Clinically Selected Patients With Advanced Non-Small-Cell Lung Cancer in Asia (IPASS). J. Clin. Oncol. 2011, 29, 2866-2874. Available online: https:/ /www.ncbi.nlm.nih.gov/pubmed/21670455 (accessed on 10 September 2021). [CrossRef]

12. Mitsudomi, T.; Morita, S.; Yatabe, Y.; Negoro, S.; Okamoto, I.; Tsurutani, J.; Seto, T.; Satouchi, M.; Tada, H.; Hirashima, T.; et al. Gefitinib versus Cisplatin Plus Docetaxel in Patients with Non-Small-Cell Lung Cancer Harbouring Mutations of the Epidermal Growth Factor Receptor (WJTOG3405): An Open Label, Randomised Phase 3 Trial. Lancet Oncol. 2010, 11, 121-128. Available online: https: / / www.ncbi.nlm.nih.gov/pubmed/20022809 (accessed on 10 September 2021). [CrossRef]

13. Perol, M.; Chouaid, C.; Perol, D.; Barlési, F.; Gervais, R.; Westeel, V.; Crequit, J.; Léna, H.; Vergnenègre, A.; Zalcman, G.; et al. Randomized, Phase III Study of Gemcitabine or Erlotinib Maintenance Therapy versus Observation, with Predefined Second-Line Treatment, after Cisplatin-Gemcitabine Induction Chemotherapy in Advanced Non-Small-Cell Lung Cancer. J. Clin. Oncol. 2012, 30, 3516-3524. Available online: https://www.ncbi.nlm.nih.gov/pubmed/22949150 (accessed on 10 September 2021). [CrossRef]

14. Rosell, R.; Carcereny, E.; Gervais, R.; Vergnenegre, A.; Massuti, B.; Felip, E.; Palmero, R.; Garcia-Gomez, R.; Pallares, C.; Sanchez, J.M.; et al. Erlotinib versus Standard Chemotherapy as First-Line Treatment for European Patients with Advanced EGFR Mutation-Positive Non-Small-Cell Lung Cancer (EURTAC): A Multicentre, Open-Label, Randomised Phase 3 Trial. Lancet Oncol. 2012, 13, 239-246. Available online: https:/ / www.ncbi.nlm.nih.gov/pubmed/22285168 (accessed on 10 September 2021). [CrossRef]

15. Sequist, L.V.; Yang, J.C.-H.; Yamamoto, N.; Obyrne, K.; Hirsh, V.; Mok, T.; Geater, S.L.; Orlov, S.; Tsai, C.-M.; Boyer, M.; et al. Phase III Study of Afatinib or Cisplatin Plus Pemetrexed in Patients with Metastatic Lung Adenocarcinoma With EGFR Mutations. J. Clin. Oncol. 2013, 31, 3327-3334. Available online: https:/ / www.ncbi.nlm.nih.gov/pubmed/23816960 (accessed on 10 September 2021). [CrossRef] [PubMed]

16. Zhou, C.; Wu, Y.L.; Chen, G.; Feng, J.; Liu, X.Q.; Wang, C.; Zhang, S.; Wang, J.; Zhou, S.; Ren, S.; et al. Erlotinib versus Chemotherapy as First-Line Treatment for Patients with Advanced EGFR Mutation-Positive Non-Small-Cell Lung Cancer (OPTIMAL, CTONG-0802): A Multicentre, Open-Label, Randomised, Phase 3 Study. Lancet Oncol. 2011, 12, 735-742. Available online: https: / / www.ncbi.nlm.nih.gov / pubmed/21783417 (accessed on 10 September 2021). [CrossRef]

17. Wu, Y.-L.; Hirsh, V.; Sequist, L.V.; Hu, C.-P.; Feng, J.; Lu, S.; Huang, Y.; Schuler, M.; Mok, T.; Yamamoto, N.; et al. Does EGFR Mutation Type Influence Patient-Reported Outcomes in Patients with Advanced EGFR Mutation-Positive Non-Small-Cell Lung Cancer? Analysis of Two Large, Phase III Studies Comparing Afatinib with Chemotherapy (LUX-Lung 3 and LUX-Lung 6). Patient 2017, 11, 131-141. Available online: https:/ / www.ncbi.nlm.nih.gov/pubmed/29178024 (accessed on 10 September 2021). [CrossRef] [PubMed]

18. Hanna, N.; Johnson, D.; Temin, S.; Baker, S.; Brahmer, J.; Ellis, P.M.; Giaccone, G.; Hesketh, P.J.; Jaiyesimi, I.; Leighl, N.B.; et al. Systemic Therapy for Stage IV Non-Small-Cell Lung Cancer: American Society of Clinical Oncology Clinical Practice Guideline Update. J. Clin. Oncol. 2017, 35, 3484-3515. Available online: https://www.ncbi.nlm.nih.gov/pubmed/28806116 (accessed on 10 September 2021). [CrossRef] [PubMed]

19. Postmus, P.E.; Kerr, K.M.; Oudkerk, M.; Senan, S.; Waller, D.A.; Vansteenkiste, J.; Escriu, C.; Peters, S.; ESMO Guidelines Committee. Early and locally advanced non-small-cell lung cancer (NSCLC): ESMO Clinical Practice Guidelines for Diagnosis, Treatment and Follow-Up. Ann. Oncol. 2017, 28 (Suppl. 4), iv1-iv21. Available online: https:/ /www.ncbi.nlm.nih.gov/pubmed/ 28881918 (accessed on 10 September 2021). [CrossRef] [PubMed]

20. Ramalingam, S.S.; Yang, J.C.-H.; Lee, C.K.; Kurata, T.; Kim, D.-W.; John, T.; Nogami, N.; Ohe, Y.; Mann, H.; Rukazenkov, Y.; et al. Osimertinib As First-Line Treatment of EGFR Mutation-Positive Advanced Non-Small-Cell Lung Cancer. J. Clin. Oncol. 2018, 36, 841-849. Available online: https:/ / www.ncbi.nlm.nih.gov/pubmed/28841389 (accessed on 10 September 2021). [CrossRef]

21. Mariano, C.; Bosdet, I.; Karsan, A.; Ionescu, D.; Murray, N.; Laskin, J.J.; Zhai, Y.; Melosky, B.; Sun, S.; Ho, C. A PopulationBased Review of the Feasibility of Platinum-Based Combination Chemotherapy after Tyrosine Kinase Inhibition in EGFR Mutation Positive Non-Small Cell Lung Cancer Patients with Advanced Disease. Lung Cancer 2014, 83, 73-77. Available online: https: / / www.ncbi.nlm.nih.gov/pubmed/24192511 (accessed on 10 September 2021). [CrossRef]

22. Law, S.C.; Chooback, N.; Cheryl, H.; Melosky, B. Outcome Differences Between First- and Second generation EGFR Inhibitors in Advanced EGFR Mutated NSCLC in a Large Population-based Cohort. Clin. Lung Cancer 2019, 20, e576-e583. Available online: https:/ / pubmed.ncbi.nlm.nih.gov/31178389/ (accessed on 10 September 2021).

23. Tudor, R.A.; D'Silva, A.; Tremblay, A.; MacEachern, P.; Morris, D.; Brenner, D.; Kopciuk, K.; Bebb, D.G. Beyond DiseaseProgression: Clinical Outcomes after EGFR-TKIs in a Cohort of EGFR Mutated NSCLC Patients. PLoS ONE 2017, 12 , e0181867. Available online: https:/ / www.ncbi.nlm.nih.gov/pubmed/28777825 (accessed on 10 September 2021). [CrossRef] [PubMed]

24. Therasse, P.; Arbuck, S.G.; Eisenhauer, E.A.; Wanders, J.; Kaplan, R.S.; Rubinstein, L.; Verweij, J.; Van Glabbeke, M.; Van Oosterom, A.T.; Christian, M.C.; et al. New Guidelines to Evaluate the Response to Treatment in Solid Tumors. J. Natl. Cancer Inst. 2000, 92, 205-216. Available online: https:/ / www.ncbi.nlm.nih.gov / pubmed/10655437 (accessed on 10 September 2021). [CrossRef]

25. National Comprehensive Cancer Network (NCCN). NCCN Clinical Practice Guidelines in Oncology: Non-Small Cell Lung Cancer. V7. 2019. Available online: https://www2.tri-kobe.org/nccn/guideline/lung/english/non_small.pdf (accessed on 10 September 2021). 
26. Soria, J.-C.; Ohe, Y.; Vansteenkiste, J.; Reungwetwattana, T.; Chewaskulyong, B.; Lee, K.H.; Dechaphunkul, A.; Imamura, F.; Nogami, N.; Kurata, T.; et al. Osimertinib in Untreated EGFR-Mutated Advanced Non-Small-Cell Lung Cancer. N. Engl. J. Med. 2018, 378, 113-125. Available online: https:/ /www.ncbi.nlm.nih.gov/pubmed/29151359 (accessed on 10 September 2021). [CrossRef]

27. Zou, B.; Lee, V.H.F.; Chen, L.; Ma, L.; Wang, D.D.; Yan, H. Deciphering Mechanisms of Acquired T790M Mutation after EGFR Inhibitors for NSCLC by Computational Simulations. Sci. Rep. 2017, 7, 6595. Available online: https://www.ncbi.nlm.nih.gov/ pubmed/28747773 (accessed on 10 September 2021). [CrossRef]

28. Fogli, S.; Polini, B.; Del Re, M.; Petrini, I.; Passaro, A.; Crucitta, S.; Rofi, E.; Danesi, R. EGFR-TKIs in Non-Small-Cell Lung Cancer: Focus on Clinical Pharmacology and Mechanisms of Resistance. Pharmacogenomics 2018, 19, 727-740. Available online: https:/ / www.ncbi.nlm.nih.gov/pubmed/29785875 (accessed on 10 September 2021). [CrossRef] [PubMed]

29. Oxnard, G.R.; Arcila, M.E.; Sima, C.S.; Riely, G.J.; Chmielecki, J.; Kris, M.; Pao, W.; Ladanyi, M.; Miller, V.A. Acquired Resistance to EGFR Tyrosine Kinase Inhibitors in EGFR-Mutant Lung Cancer: Distinct Natural History of Patients with Tumors Harboring the T790M Mutation. Clin. Cancer Res. 2010, 17, 1616-1622. Available online: https://www.ncbi.nlm.nih.gov/pubmed/21135146 (accessed on 10 September 2021). [CrossRef]

30. Marinis, F.; Wu, Y.L.; de Castro, G., Jr.; Chang, G.C.; Chen, Y.M.; Cho, B.C.; Freitas, H.C.; Jiang, L.; Kim, S.W.; Martin, C.; et al. ASTRIS: A Global Real-World Study of Osimertinib in >3000 Patients with EGFR T790M Positive Non-Small-Cell Lung Cancer. Future Oncol. 2019, 15, 3003-3014. Available online: https:/ / www.ncbi.nlm.nih.gov/pubmed/31339357 (accessed on 10 September 2021). [CrossRef]

31. Mok, T.S.; Wu, Y.L.; Ahn, M.J.; Garassino, M.C.; Kim, H.R.; Ramalingam, S.S.; Shepherd, F.A.; He, Y.; Akamatsu, H.; Theelen, W.M.S.E.; et al. Osimertinib or Platinum-Pemetrexed in EGFR T790M-Positive Lung Cancer. N. Engl. J. Med. 2017, 376, 629-640. Available online: https://www.ncbi.nlm.nih.gov/pubmed/27959700 (accessed on 10 September 2021). [CrossRef] [PubMed]

32. Rossi, A.; Di Maio, M. LUX-Lung: Determining the Best EGFR Inhibitor in NSCLC? Lancet Oncol. 2015, 16, 118-119. Available online: https: / / www.ncbi.nlm.nih.gov / pubmed/25589190 (accessed on 10 September 2021). [CrossRef]

33. Ahn, M.-J.; Tsai, C.-M.; Shepherd, F.A.; Bazhenova, L.; Sequist, L.V.; Hida, T.; Yang, J.C.H.; Ramalingam, S.S.; Mitsudomi, T.; Jänne, P.A.; et al. Osimertinib in Patients with T790M Mutation-Positive, Advanced Non-Small Cell Lung Cancer: Long-Term Follow-Up from a Pooled Analysis of 2 Phase 2 Studies. Cancer 2019, 125, 892-901. Available online: https:/ / www.ncbi.nlm.nih. gov/pubmed/30512189 (accessed on 10 September 2021). [CrossRef]

34. Seung, S.; Hurry, M.; Walton, R.; Evans, W. Real-World Treatment Patterns and Survival in Stage IV Non-Small-Cell Lung Cancer in Canada. Curr. Oncol. 2020, 27, 361-367. Available online: https://www.ncbi.nlm.nih.gov/pubmed/32905294 (accessed on 10 September 2021). [CrossRef] [PubMed]

35. Hotta, K.; Suzuki, E.; Di Maio, M.; Chiodini, P.; Fujiwara, Y.; Takigawa, N.; Ichihara, E.; Reck, M.; Manegold, C.; Pilz, L.; et al. Progression-Free Survival and Overall Survival in Phase III Trials of Molecular-Targeted Agents in Advanced Non-Small-Cell Lung Cancer. Lung Cancer 2013, 79, 20-26. Available online: https://www.ncbi.nlm.nih.gov/pubmed/23164554 (accessed on 10 September 2021). [CrossRef] [PubMed]

36. Yang, J.J.; Zhou, Q.; Yan, H.H.; Zhang, X.C.; Chen, H.J.; Tu, H.Y.; Wang, Z.; Xu, C.R.; Su, J.; Wang, B.C.; et al. A phase III Randomised Controlled Trial of Erlotinib vs Gefitinib in Advanced Non-Small Cell Lung Cancer with EGFR Mutations. Br. J. Cancer 2017, 116, 568-574. Available online: https:/ / www.ncbi.nlm.nih.gov/pubmed/28103612 (accessed on 10 September 2021). [CrossRef] [PubMed]

37. Yusuf, D.; Walton, R.N.; Hurry, M.; Farrer, C.; Bebb, D.G.; Cheung, W.Y. Population-Based Treatment Patterns and Outcomes for Stage III Non-Small Cell Lung Cancer Patients: A Real-World Evidence Study. Am. J. Clin. Oncol. 2020, 43, 615-620. Available online: https: / / www.ncbi.nlm.nih.gov/pubmed/32889830 (accessed on 10 September 2021). [CrossRef]

38. Li, J.; Qu, L.; Wei, X.; Gao, H.; Wang, W.; Qin, H.; Tang, C.; Guo, W.; Wang, H.; Liu, X. Clinical observation of EGFR-TKI as a First-Line Therapy on Advanced Non-Small Cell Lung Cancer. Zhongguo Fei Ai Za Zhi 2012, 15, 299-304. Available online: https://www.ncbi.nlm.nih.gov/pubmed/22613337 (accessed on 10 September 2021). [PubMed]

39. Fujita, Y.; Kinoshita, M.; Ozaki, T.; Takano, K.; Kunimasa, K.; Kimura, M.; Inoue, T.; Tamiya, M.; Nishino, K.; Kumagai, T.; et al. The Impact of EGFR Mutation Status and Single Brain Metastasis on the Survival of Non-Small-Cell Lung Cancer Patients with Brain Metastases. Neuro-Oncol. Adv. 2020, 2, vdaa064. Available online: https://www.ncbi.nlm.nih.gov/pubmed/32642715 (accessed on 10 September 2021). [CrossRef] [PubMed]

40. Park, K.; Tan, E.-H.; O’Byrne, K.; Zhang, L.; Boyer, M.; Mok, T.; Hirsh, V.; Yang, J.C.-H.; Lee, K.H.; Lu, S.; et al. Afatinib versus Gefitinib as First-Line Treatment of Patients with EGFR Mutation-Positive Non-Small-Cell Lung Cancer (LUX-Lung 7): A Phase 2B, Open-Label, Randomised Controlled Trial. Lancet Oncol. 2016, 17, 577-589. Available online: https://www.ncbi.nlm.nih.gov/ pubmed/27083334 (accessed on 10 September 2021). [CrossRef]

41. Ezeife, D.A.; Melosky, B.; Tudor, R.; Lin, S.; Lau, A.; Panzarella, T.; Leighl, N.B. Afatinib in Advanced Pretreated Non-Small-Cell Lung Cancer-A Canadian Experience. Curr. Oncol. 2018, 25, 385-390. Available online: https://www.ncbi.nlm.nih.gov/ pubmed/30464688 (accessed on 10 September 2021). [CrossRef] 
42. Katakami, N.; Atagi, S.; Goto, K.; Hida, T.; Horai, T.; Inoue, A.; Ichinose, Y.; Koboyashi, K.; Takeda, K.; Kiura, K.; et al. LUX-Lung 4: A Phase II Trial of Afatinib in Patients with Advanced Non-Small-Cell Lung Cancer Who Progressed during Prior Treatment with Erlotinib, Gefitinib, or Both. J. Clin. Oncol. 2013, 31, 3335-3341. Available online: https://www.ncbi.nlm.nih.gov/pubmed/ 23816963 (accessed on 10 September 2021). [CrossRef]

43. Lin, J.J.; Cardarella, S.; Lydon, C.A.; Dahlberg, S.E.; Jackman, D.M.; Jänne, P.A.; Johnson, B.E. Five-Year Survival in EGFR -Mutant Metastatic Lung Adenocarcinoma Treated with EGFR-TKIs. J. Thorac. Oncol. 2016, 11, 556-565. Available online: https:/ / www.ncbi.nlm.nih.gov/pubmed/26724471 (accessed on 10 September 2021). [CrossRef] 